\title{
Use of hexamethyldisiloxane for p-type microcrystalline silicon oxycarbide layers
}

\author{
Prabal Goyal ${ }^{1,2,3, a}$, Junegie Hong ${ }^{1,3}$, Farah Haddad ${ }^{2,3}$, Jean-Luc Maurice ${ }^{2,3}$, \\ Pere Roca i Cabarrocas ${ }^{2,3}$, and Erik Johnson ${ }^{2,3}$ \\ 1 Air Liquide, Centre de Recherche Paris Saclay, 78354 Jouy-en-Josas, France \\ 2 Laboratoire de Physique des Interfaces et des Couches Minces, CNRS, Ecole Polytechnique, 91128 Palaiseau, France \\ 3 LPICM- LPICM, CNRS, Ecole polytechnique, Université Paris-Saclay, 91128 Palaiseau, France
}

Received: 6 June 2015 / Received in final form: 8 November 2015 / Accepted: 30 November 2015

Published online: 13 January 2016

(C) Goyal et al., published by EDP Sciences, 2016

\begin{abstract}
The use of hexamethyldisiloxane (HMDSO) as an oxygen source for the growth of p-type siliconbased layers deposited by Plasma Enhanced Chemical Vapor Deposition is evaluated. The use of this source led to the incorporation of almost equivalent amounts of oxygen and carbon, resulting in microcrystalline silicon oxycarbide thin films. The layers were examined with characterisation techniques including Spectroscopic Ellipsometry, Dark Conductivity, Fourier Transform Infrared Spectroscopy, Secondary Ion Mass Spectrometry and Transmission Electron Microscopy to check material composition and structure. Materials studies show that the refractive indices of the layers can be tuned over the range from 2.5 to 3.85 (measured at $600 \mathrm{~nm}$ ) and in-plane dark conductivities over the range from $10^{-8} \mathrm{~S} / \mathrm{cm}$ to $1 \mathrm{~S} / \mathrm{cm}$, suggesting that these doped layers are suitable for solar cell applications. The p-type layers were tested in single junction amorphous silicon p-i-n type solar cells.
\end{abstract}

\section{Introduction}

The improvement of thin-film doped layers deposited by plasma enhanced chemical vapor deposition (PECVD) - used in thin film silicon and heterojunction silicon solar cells - provides a great opportunity for increased device performance and cost reduction. These films are necessary to provide an electron-hole pair separation mechanism in the absorber layer, but they are also a source of parasitic absorption $[1,2]$. However, these layers can provide greater control over optical reflection if properly designed. The most common materials for doped amorphous or microcrystalline layers in thin film silicon solar cells are silicon, silicon-carbon alloys [3] and siliconoxygen alloys [4]. In particular, doped microcrystalline silicon oxide $\left(\mu \mathrm{c}-\mathrm{SiO}_{x}: \mathrm{H}\right)$ is a material which has gained scientific interest because of it having a reduced optical absorption and low refractive index, while still generating sufficient built-in potential across the absorber layer for electron-hole separation [5-8]. It has been demonstrated that it is possible to control the refractive index $(n)$ of undoped and doped $\mu \mathrm{c}-\mathrm{SiO}_{x}: \mathrm{H}$ in the range from $1.8^{-}$ $3.6[9-11]$ and that these layers can be designed for several functions in thin film silicon solar cells, namely as a doped layer or as an intermediate reflector layer (IRL) [12].

\footnotetext{
${ }^{a}$ e-mail: prabal.goyal@polytechnique.edu
}

Table 1. Values of refractive index $(n)$ in literature for different $\mu \mathrm{c}-\mathrm{SiO}_{x}: \mathrm{H}$ type materials.

\begin{tabular}{ccc}
\hline Material & Function & $n$ \\
\hline $\mathrm{p}-\mu \mathrm{c}-\mathrm{SiO}_{x}: \mathrm{H}$ & p-type layer & $2.97-3.5[5,13]$ \\
$\mathrm{n}-\mu \mathrm{c}-\mathrm{SiO}_{x}: \mathrm{H}$ & n-type layer + IRL & $1.8-2.6[9,10,14,15]$ \\
$\mathrm{SiO}_{x}$ & IRL & $2.0[12,16]$ \\
\hline
\end{tabular}

Table 1 gives a summary of $n$ values reported in the literature for such films.

The electrical conductivity of doped $\mu \mathrm{c}-\mathrm{SiO}_{x}: \mathrm{H}$ is attributed to the presence of doped microcrystalline silicon filaments in an amorphous silicon oxide matrix, which results in an out-of-plane conductivity of the layers above $10^{-5} \mathrm{~S} / \mathrm{cm}$, while their in-plane conductivities are below $10^{-10} \mathrm{~S} / \mathrm{cm}[9]$. The amorphous silicon oxide matrix consists of Si-Si, Si-O-H as well Si-O-Si bonds [17]. Carbon-dioxide $\left(\mathrm{CO}_{2}\right)$ mixed with silane $\left(\mathrm{SiH}_{4}\right)$ and hydrogen $\left(\mathrm{H}_{2}\right)$ (with p-type or n-type doping gas) is the most common chemistry for depositing doped $\mu \mathrm{c}-\mathrm{SiO}_{x}: \mathrm{H}$. In this work, we explore the use of hexamethyldisiloxane $\left(\mathrm{C}_{6} \mathrm{H}_{18} \mathrm{OSi}_{2}, \mathrm{HMDSO}\right)$ as an alternative oxygen and carbon source for p-type microcrystalline silicon oxycarbide layers. Figure 1 shows the chemical structure of hexamethyldisiloxane (HMDSO). In such molecules, the desired Si-O-Si bonds already pre-exist, whereas for $\mathrm{CO}_{2}$, dissociation in the plasma produces atomic $\mathrm{O}[9]$ which is 
<smiles>C[Si](C)(C)O[Si](C)(C)C</smiles>

Fig. 1. Structure of hexamethyldisiloxane (HMDSO).

then incorporated into bonds at the film growth surface. This may result in the less desirable Si-O-H configuration, which is a deep electron trap $[18,19]$. HMDSO has already been used in the literature to deposit thermally stable $\mathrm{SiO}_{2}$ layers [20] and dielectric barrier layers [21] It was suggested that the $\mathrm{Si}-\mathrm{C}$ bonds dissociate first and that the Si-O-Si bond remains intact during HMDSO decomposition in a plasma [22].

\section{Experimental method}

HMDSO is a liquid precursor usually stored in a canister. The canister was installed in a commercial liquidsource gas distribution system (Mini $\mathrm{CANDI}^{\mathrm{TM}}$ ) and the liquid was kept heated at $60{ }^{\circ} \mathrm{C}$ to increase the vapor pressure. The resulting gaseous HMDSO was injected in a PECVD chamber and was mixed with hydrogen $\left(\mathrm{H}_{2}\right)$, silane $\left(\mathrm{SiH}_{4}\right)$ and diborane $(1 \%$ dilution in $\mathrm{Ar})$. The PECVD reactor is a Plassys CVD 300 operated at a fixed $\mathrm{RF}$ frequency of $13.56 \mathrm{MHz}$. The distance between the electrodes is $25 \mathrm{~mm}$. The layers were deposited on Corning Glass substrates and crystalline silicon float zone (FZ) wafers. To study the influence of HMDSO on the film properties, the HMDSO flow rate was varied from 0 to $1.2 \mathrm{sccm}$ while other process parameters were kept constant. The $\mathrm{RF}$ power was fixed at $30 \mathrm{~W}\left(\sim 0.17 \mathrm{~W} / \mathrm{cm}^{2}\right)$, pressure at 2.5 Torr, substrate temperature at $150{ }^{\circ} \mathrm{C}$, and gas flows in the ratio $\mathrm{H}_{2} / \mathrm{SiH}_{4} / \mathrm{B}_{2} \mathrm{H}_{6}=2000 / 4 / 1.6$.

The layers deposited on glass substrates were characterized with an ex-situ spectroscopic ellipsometer (UVISEL from Horiba Jobin Yvon) in the range from $1.5 \mathrm{eV}(827 \mathrm{~nm})$ to $4.5 \mathrm{eV}(276 \mathrm{~nm})$. The surface profile of the layers was analyzed by a conductive probe atomic force microscope (Resiscope II) which can measure resistances in the range of $10^{2}$ to $10^{12} \Omega$. The in-plane dark conductivity $(\sigma)$ of the layers was measured using a co-planar aluminium electrode configuration in a temperature $(T)$ range from $40{ }^{\circ} \mathrm{C}$ to $125{ }^{\circ} \mathrm{C}$. From the slope of the $\ln (\sigma)$ plotted versus $1 / T$, activation energy of the conductivity of the layers $\left(E_{a}\right)$ of the layers was estimated using $\ln \sigma=-E_{a} / k T+\ln \sigma_{o}$ where $k$ is the Boltzmann constant and $\sigma_{0}$ is the conductivity prefactor.

The composition of gas species in the plasma was studied using a Fourier Transform Infrared (FT-IR) spectrometer installed downstream of the dry process pump. The spectral range of this gas-phase FT-IR spectrometer is $1100-4000 \mathrm{~cm}^{-1}$. The molecular bond configuration in the layers was studied with another FT-IR spectrometer (Nicolet 6700 with a Mercury Cadmium Telluride detector cooled by liquid nitrogen). The FT-IR spectra were acquired on the layers deposited on FZ c-Si substrates over a range from $500-4000 \mathrm{~cm}^{-1}$. The elemental composition of the layers was checked using secondary ion mass spectroscopy (SIMS). The local characterisation of the phase ( $\mu \mathrm{c}-\mathrm{Si}: \mathrm{H}$ and a-Si:H) was performed by transmission electron microscopy (TEM) using selected area electron diffraction (SAED) and high-resolution TEM (HRTEM).

Finally, these layers were used as the p-type doped layer in single junction p-i-n solar cells. $\mathrm{ZnO}: \mathrm{Al}$ $(1 \mu \mathrm{m})$ was sputtered on Corning Glass (sheet resistance $\sim 10 \Omega$ /square) as a front contact and was etched in $\mathrm{HCl}$ solution $(0.5 \%)$ for $40 \mathrm{~s}$. More details about the preparation of such substrates can be found in reference [23]. The p-type layers were deposited with an HMDSO flow rate in a range from 0 to $1.2 \mathrm{sccm}$. The thickness of the i-layer (a-Si:H) is $300 \mathrm{~nm}$ and that of the n-layer $\left(\mathrm{n}-\mu \mathrm{c}-\mathrm{SiO}_{x}: \mathrm{H}\right)$ was $30 \mathrm{~nm}$. To isolate the influence of the p-layers, all of the i-layers and n-layers were co-deposited, and therefore were the same on all substrates. However, this necessitates a vacuum break at the p/i interface. Furthermore, due to the lack of an n-type dopant source in the HMDSO equipped reactor, a vacuum break was also necessary at the $\mathrm{i} / \mathrm{n}$ interface as the samples were transferred to another reactor. To check for any disproportionate impact of a vacuum break on HMDSO layers, standard p-a-Si:H and p- $\mu \mathrm{c}-\mathrm{SiO}_{x}: \mathrm{H}$ (deposited using $\mathrm{CO}_{2}$ ) layers were used as references during the same i-layer and n-layer deposition. The back contact $(\mathrm{ZnO} / \mathrm{Ag})$ was deposited by sputtering. The solar cells were then annealed at $150{ }^{\circ} \mathrm{C}$ for $30 \mathrm{~min}$. For each p-type layer, six solar cells were fabricated and the active area of a solar cell is about $0.125 \mathrm{~cm}^{2}$. The $J-V$ characteristics were measured under 1 sun at $25^{\circ} \mathrm{C}$, and the external quantum efficiency (EQE) of the p-i-n solar cells was measured under short circuit conditions, and certified using a calibrated diode.

\section{Results}

\subsection{Ellipsometry}

Figure 2 shows the imaginary part of the pseudodielectric function, $\left\langle\varepsilon_{2}\right\rangle$ of the layers deposited using different HMDSO flow rates. The thickness of the layers is around $30 \mathrm{~nm}$.

In Figure 2, we see that as HMDSO flow rate increases, the intensity of the $\left\langle\varepsilon_{2}\right\rangle$ spectra at high energy $(\sim 3.7 \mathrm{eV})$ decreases. The fitting of the ellipsometry spectra was done with the Delta-Psi2 software using a two layer model composed of a bulk layer and a roughness layer. In this optical modeling, we used an effective medium approximation based on Bruggeman's theory [24] to calculate the optical dielectric functions of each layer. The bulk layer model consists of three phases: amorphous silicon, small grain microcrystalline silicon and $\mathrm{SiO}_{2}$. The percentage of small grain microcrystalline silicon in the model indicates the crystalline volume fraction $\left(X_{c}\right)$ in the layer, and has been verified to be consistent with Raman scattering (not shown). The roughness layer consists of a 50/50 mix of 


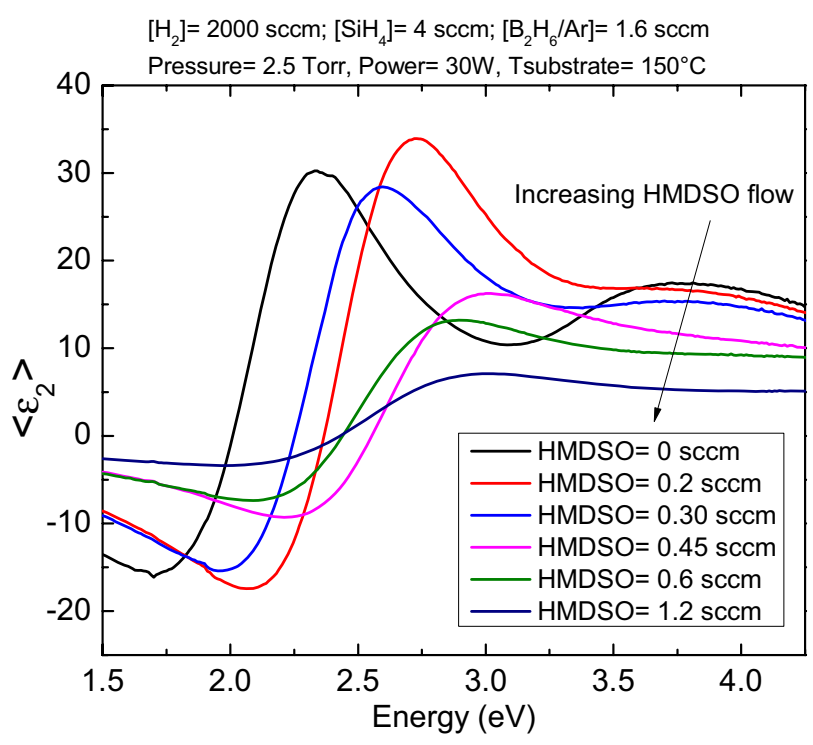

Fig. 2. Imaginary part of pseudo-dielectric function of layers deposited using different HMDSO flow rates, measured by spectroscopic ellipsometry (SE).

voids and microcrystalline silicon. More details about the optical modeling can be found in reference [8]. The fitting of the bulk layer allows one to estimate the thickness (or deposition rate) and the optical parameters $(n, \alpha)$ of the deposited materials. Figure 3 shows the crystalline fraction $\left(X_{c}\right)$ and deposition rate $\left(r_{d}\right)$. The refractive index $(n)$ at $600 \mathrm{~nm}$ and absorption coefficient $(\alpha)$ at $400 \mathrm{~nm}$ (extracted from the ellipsometric modelling) as a function of the HMDSO flow rate are shown in Figure 4. Although the model does not explicitly include an a-SiC:H component, it is assumed that the inclusion of a-Si:H in the optical model allows one to account for the incorporation of oxygen and carbon into the amorphous phase of the film. Regardless, the accuracy in the thickness, $n$, and $\alpha$ would not be affected by the details of the model as long as the fit to the data remains good. However, the extracted value of $X_{c}$ is more strongly influenced by inaccuracies in the model. Nevertheless, based on comparison with Raman measurements, we can assert that the value of $X_{c}$ obtained from ellipsometry is accurate to within $\pm 4 \%$ absolute for these samples.

Figure 3 shows that as the HMDSO flow rate increases from 0 to $1.2 \mathrm{sccm}$, the deposition rate $\left(r_{d}\right)$ increases from $0.3 \AA / \mathrm{s}$ to $0.6 \AA / \mathrm{s}$, while the crystalline fraction $\left(X_{c}\right)$ decreases. When the HMDSO flow rate is zero, the layer is microcrystalline with $X_{c} \sim 60 \%$. However, as the incorporation of oxygen and carbon in the films inhibit microcrystalline growth, at high flow rate $(1.2 \mathrm{sccm})$ of $\mathrm{HMDSO}, X_{c}$ is almost zero. For p-type nc-SiO $\mathrm{S}_{x}$ layers deposited with $\mathrm{CO}_{2}$ as the $\mathrm{O}$ source under similar conditions [5], $X_{c}$ determined by Raman spectroscopy also gave values in the range of $40 \%$ to $75 \%$. It has been suggested that for $\mathrm{p}-\mu \mathrm{c}-\mathrm{SiO}_{x}: \mathrm{H}$, the best performance of solar cells is obtained when using p-type layers deposited at the transition region between $\mu \mathrm{c}-\mathrm{Si}: \mathrm{H}$ and a-Si:H [13].

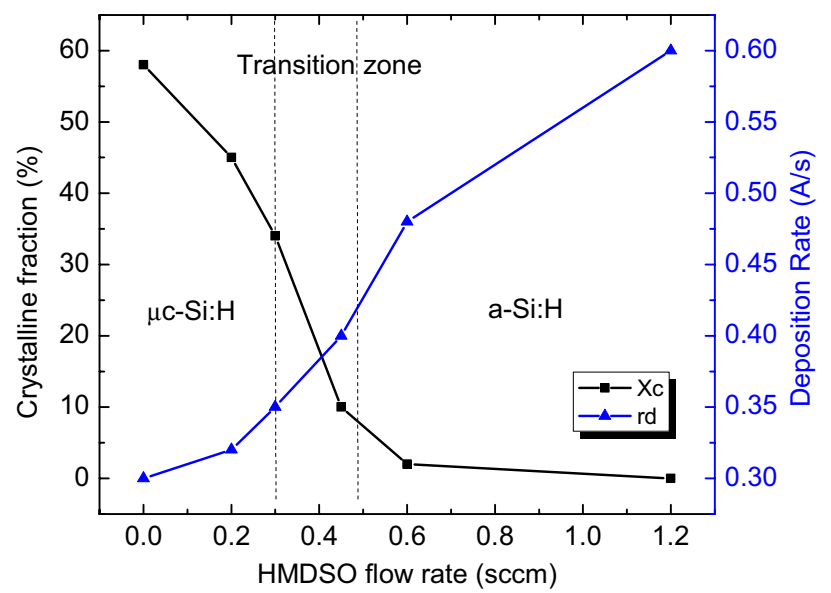

Fig. 3. Crystalline fraction $(X c)$ and deposition rate $\left(r_{d}\right)$ of HMDSO layers as a function of HMDSO flow rate, as obtained by ellipsometric modeling.

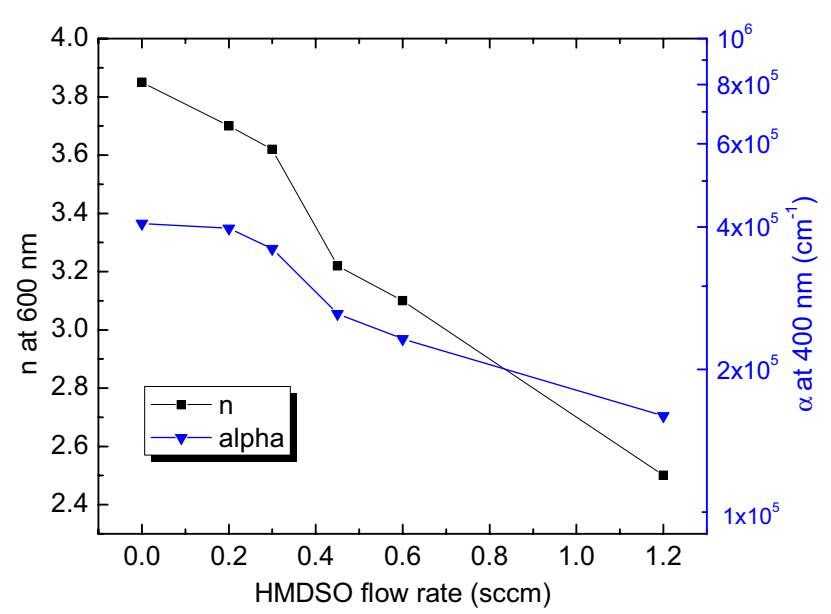

Fig. 4. Optical parameters $n(600 \mathrm{~nm})$ and $\alpha(400 \mathrm{~nm})$ of the HMDSO layers.

Figure 4 shows that as the HMDSO flow rate increases, the refractive index ( $n$ at $600 \mathrm{~nm}$ ) decreases from 3.85 to 2.5. It is possible to obtain values of $n$ down to 1.8 with even higher flows of HMDSO (above $1.2 \mathrm{sccm}$ ) but the inplane conductivity of these layers is less than $10^{-12} \mathrm{~S} / \mathrm{cm}$ which is out of the range of our in-plane conductivity measurement set up. These films are considered as to be $\mathrm{SiO}_{x}$-rich dielectric films with a high band gap $\left(E_{g}\right.$ above $3 \mathrm{eV}$ ) and are not within the scope of this paper. Also we note in Figure 4 that $\alpha$ decrease from $4 \times 10^{5} \mathrm{~cm}^{-1}$ to $2 \times 10^{5} \mathrm{~cm}^{-1}$ as the HMDSO flow rate increases from 0 to $1.2 \mathrm{sccm}$. Standard $\mathrm{p}-\mu \mathrm{c}-\mathrm{SiO}_{x}: \mathrm{H}$ layers deposited with $\mathrm{CO}_{2}$ as the $\mathrm{O}$ precursor under similar conditions also have $\alpha \sim 3 \times 10^{5} \mathrm{~cm}^{-1}[5]$. The sharp decrease in $n$ and $\alpha$ in the range of $0.3 \mathrm{sccm}$ to $0.45 \mathrm{sccm}$ of HMDSO could also be attributed to the change in $X_{c}$ from $35 \%$ to $10 \%$ (Fig. 3 ). Furthermore, it should be noted that in comparison with $\mathrm{p}-\mu \mathrm{c}-\mathrm{SiO}_{x}: \mathrm{H}$ layers reported in reference [14] with similar crystalline fractions of $35 \%$, our $\mathrm{p}-\mu \mathrm{c}-\mathrm{SiO}_{x} \mathrm{C}_{y}: \mathrm{H}$ layers display much higher values of $n$ (3.6 vs. 3.1). 


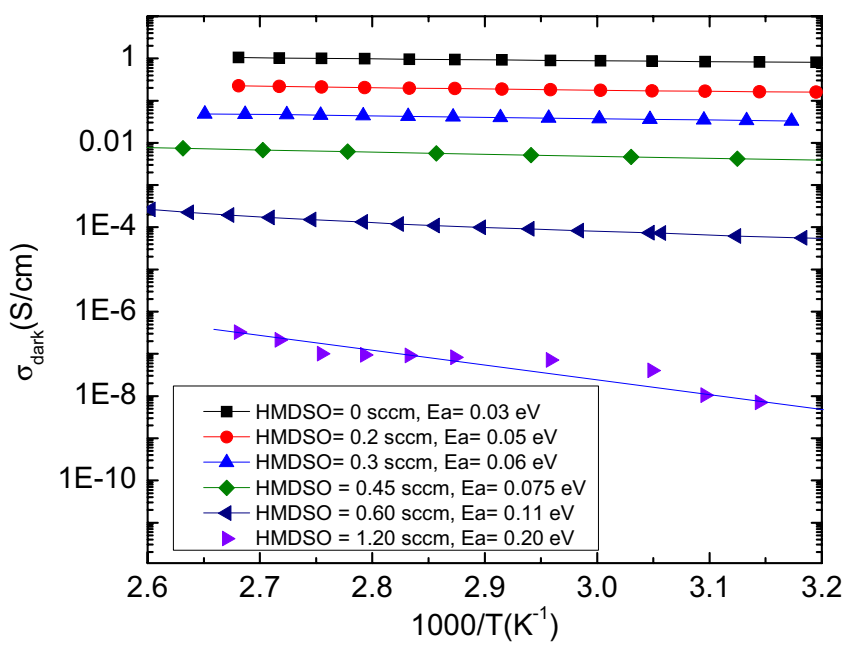

Fig. 5. Dark conductivity $(\sigma)$ and activation energy $\left(E_{a}\right)$ of layers deposited with different values of HMDSO flow rate.

\subsection{Dark conductivity and activation energy}

To check the electrical properties of the layers, the inplane conductivity of the p-type layers was measured as a function of temperature, and the results are shown in Figure 5. Also indicated in the legend are the activation energies $\left(E_{a}\right)$ of the layers (obtained from a linear fit of the data on a $\log (\sigma)$ vs. $1000 / T$ plot $)$, which for a p-type layer, provide a measure of the energy difference between the valence band edge and the Fermi level.

Figure 5 shows that the in-plane dark conductivity of the layers at room temperature decreases from $1 \mathrm{~S} / \mathrm{cm}$ to $10^{-8} \mathrm{~S} / \mathrm{cm}$ as the HMDSO flow rate increases from 0 to $1.2 \mathrm{sccm}$. This is expected because the increasing oxygen and carbon content makes the layers amorphous [25] and electrical conductivity decreases. Also the activation energy increases from $0.03 \mathrm{eV}$ to $0.20 \mathrm{eV}$, possibly due to the decrease in doping efficiency as the oxygen and carbon content in the layer increases and as the layers get more amorphous. Curiously, the sharp transition in $X_{c}$ between HMDSO flow rate of $0.3 \mathrm{sccm}$ to $0.45 \mathrm{sccm}$ is not reflected in $\sigma$ or $E_{a}$.

However, we must note that we measure here only the in-plane conductivity of the layers. For solar cells, the out-of-plane conductivity is more important. It has been demonstrated by series resistance measurements in solar cells that a layer with an in-plane conductivity below $10^{-10} \mathrm{~S} / \mathrm{cm}$ may have out-of-plane conductivity above $10^{-5} \mathrm{~S} / \mathrm{cm}$ [9]. To check if this is true for our samples, we performed conductive probe AFM (CPAFM) measurement on one of the samples (HMDSO = $0.45 \mathrm{sccm}$ ). The sample was prepared by depositing such a p-type $\mu \mathrm{c}-\mathrm{SiO}_{x} \mathrm{C}_{y}: \mathrm{H}$ layer on a conductive $\mathrm{ZnO}: \mathrm{Al}$ substrate, such that the current could flow vertically from the surface to the bottom contact. This configuration simulates the actual operation of the layer in a solar cell. Figure 6 shows the CP-AFM scan obtained for a layer with an HMDSO flow rate of $0.45 \mathrm{sccm}$.

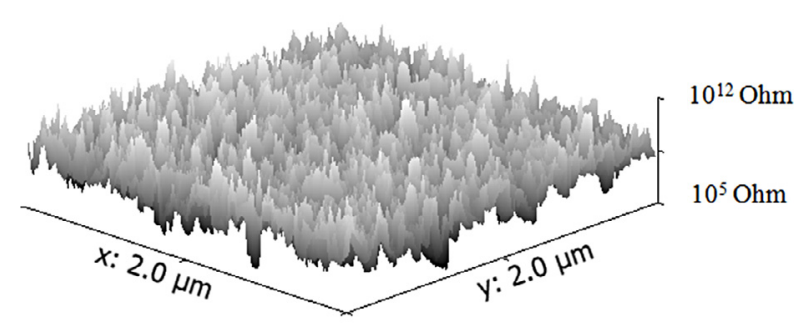

Fig. 6. Conductive probe AFM image of the layer with HMDSO flow rate of $0.45 \mathrm{sccm}$. Note that the resistance is indicated on a logarithmic scale.

Figure 6 shows that the resistance of the layer can vary by several orders of magnitude. There are some regions with a resistance of the order of $10^{12} \Omega$ while there are other regions with resistance of the order of $10^{5} \Omega$. We expect that the regions with low resistance values $\left(\sim 10^{5} \Omega\right)$ correspond to microcrystalline regions in the layer [26]. It is difficult to calculate absolute values of conductivity with this resistance data (due to tip size effects and contact resistance) but the seven orders of magnitude difference in resistance is consistent with the $\mu \mathrm{c}-\mathrm{SiO}_{x}: \mathrm{H}$ model of microcrystalline silicon filaments in an amorphous silicon oxide (oxycarbide) matrix [9]. The low dopant levels (suitable for the more ordered microcrystalline regions) and amorphous nature of the matrix combine to give very low carrier concentrations in these regions.

\subsection{Fourier Transform Infrared Spectroscopy}

To study the gas dissociation and deposition pathways, we analyze the deposition process both by measuring optical absorption in the gas phase (including the plasma), as well as in the solid phase (the thin films), both through the FT-IR technique. The gas phase FT-IR system is installed downstream of the dry process pump. Figure 7 shows the FT-IR absorption spectrum of pure HMDSO in the gas phase [27], as well as the absorption due to the gases and species once the plasma $\left(\mathrm{H}_{2}+\mathrm{SiH}_{4}+\mathrm{HMDSO}+\mathrm{B}_{2} \mathrm{H}_{6} / \mathrm{Ar}\right)$ is turned on. Also shown is the FT-IR absorption of an HMDSO p- $\mu$ c-SiO $\mathrm{C}_{y}: \mathrm{H}$ layer (p-type layer) deposited on an intrinsic FZ c-Si wafer. It should be noted that for the downstream gas-phase FT-IR system, some of the species may stick to the walls of the connecting lines and pump. Furthermore, as the range of this FT-IR is 1100$4000 \mathrm{~cm}^{-1}$, it was not possible to detect the $\mathrm{Si}-\mathrm{O}-\mathrm{Si}$ peak $\left(\sim 1070 \mathrm{~cm}^{-1}\right)$ in the gas phase.

Figure 7 shows that HMDSO has two strong absorption peaks: $\mathrm{Si}-\mathrm{CH}_{3}\left(1250 \mathrm{~cm}^{-1}\right)$ and $\mathrm{CH}_{3}\left(2950 \mathrm{~cm}^{-1}\right)$. These bond configurations are also seen when the plasma $\left(\mathrm{H}_{2}+\mathrm{SiH}_{4}+\mathrm{HMDSO}+\mathrm{B}_{2} \mathrm{H}_{6} / \mathrm{Ar}\right)$ is turned on. When the FT-IR spectrum of the plasma is compared to the p-type layer $(\mathrm{HMDSO}=0.2 \mathrm{sccm})$, there are no species of Si$\mathrm{CH}_{3}\left(1250 \mathrm{~cm}^{-1}\right)$ and $\mathrm{CH}_{3}\left(2950 \mathrm{~cm}^{-1}\right)$ in the layer, whereas Si-O-Si bending $\left(830 \mathrm{~cm}^{-1}\right)$ and Si-O-Si asymmetric stretching $\left(1070 \mathrm{~cm}^{-1}\right)$ are visible. This confirms that HMDSO dissociates in the plasma, and species such as Si-O-Si originating from HMDSO contribute to the 


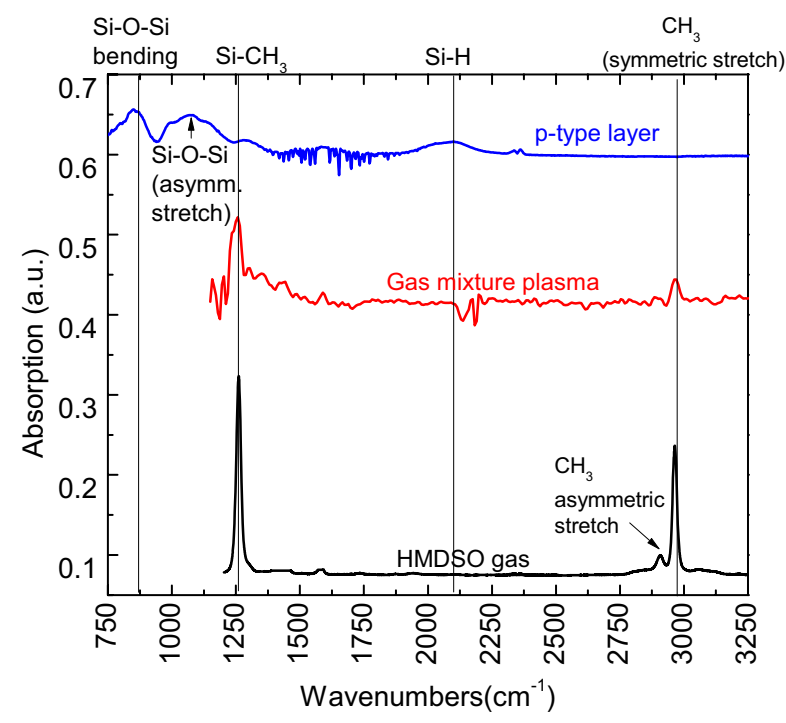

Fig. 7. FT-IR spectra of pure HMDSO in gas phase, deposition gas mixture with plasma ignited, and p-type layer $(\mathrm{HMDSO}=$ $0.2 \mathrm{sccm})$ deposited on silicon wafer.

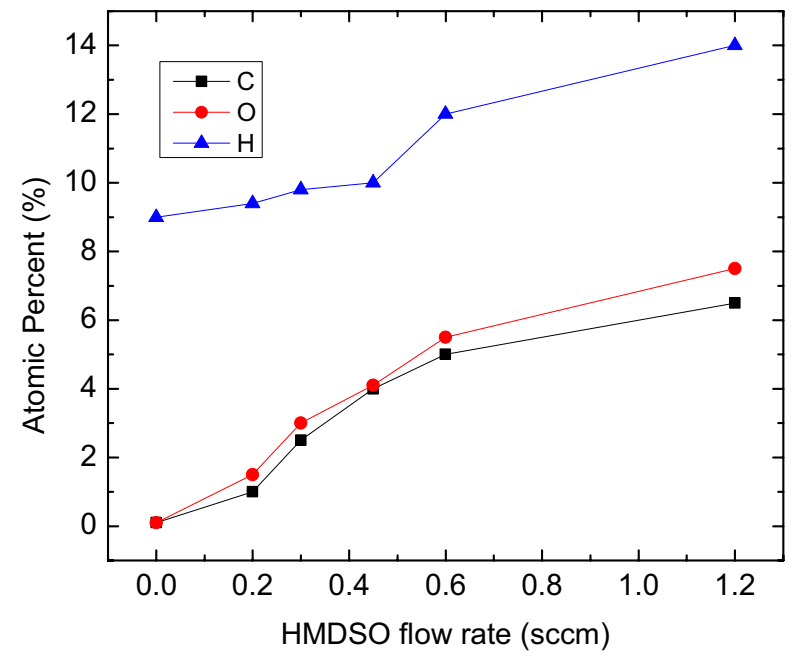

Fig. 8. Elemental composition of layers as a function of HMDSO flow rate.

deposition of the layers, while $\mathrm{CH}_{3}$ is not as efficiently incorporated into the films.

\subsection{Secondary ion mass spectrometry}

To accurately compare the elemental composition of $\mathrm{p}-\mu \mathrm{c}-\mathrm{SiO}_{x} \mathrm{C}_{y}: \mathrm{H}$ films deposited at different HMDSO flow rates, two stacks of three $\mathrm{HMDSO} \mathrm{p}-\mu \mathrm{c}-\mathrm{SiO}_{x} \mathrm{C}_{y}: \mathrm{H}$ layers each were deposited on FZ wafers for SIMS measurements. Assuming the atomic density of the layers to be that of amorphous silicon $\left(\sim 5 \times 10^{22}\right.$ at $\left./ \mathrm{cm}^{3}\right)$, the atomic concentration of elements $(\mathrm{C}, \mathrm{O}, \mathrm{H})$ in the layers was determined and is shown in Figure 8.

Figure 8 shows that as HMDSO flow rate increases, the concentrations of all three elements $(\mathrm{C}, \mathrm{O}, \mathrm{H})$ are increasing, as would be expected. In a n- $\mu \mathrm{c}-\mathrm{SiO}_{x}: \mathrm{H}$ layer de-

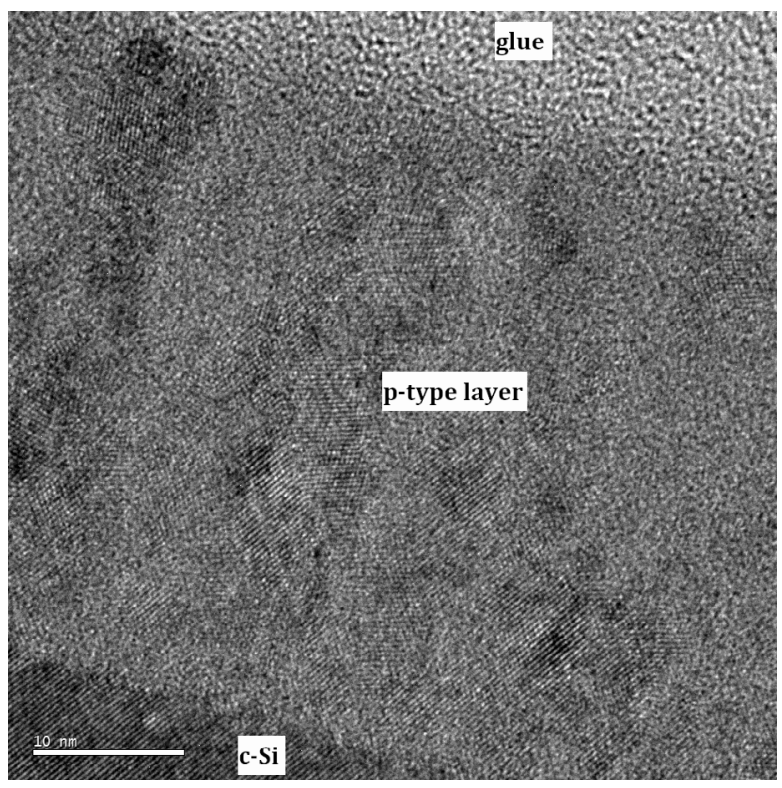

Fig. 9. HRTEM image of p-type layer at HMDSO flow rate of $0.45 \mathrm{sccm}$.

posited with $\mathrm{CO}_{2}$ as the $\mathrm{O}$ source, the atomic percentage of $\mathrm{C}$ was estimated around $2 \%$ [25]. In our case, HMDSO is an additional source of $\mathrm{C}$ and the percentage goes up to $6.5 \%$ for $1.2 \mathrm{sccm}$ of HMDSO. We expect that this extra $\mathrm{C}$ in the layers is promoting the transformation to an amorphous (and eventually dielectric) layer, in addition to the impact of $\mathrm{O}$. The hydrogen content in the layers is in the range of $10-15 \%$ which is also similar to the value reported in reference [25]. Also, we note that the percentage of $\mathrm{O}$ and $\mathrm{C}$ in the layers is comparable, which is striking given that the ratio of $\mathrm{C}$ to $\mathrm{O}$ in the HMDSO molecule is 6 to 1 , and therefore indicating that $\mathrm{O}$ is incorporated six times more efficiently than $\mathrm{C}$. The similar ratio of $\mathrm{O}$ and $\mathrm{C}$ in the layers suggests that p-type microcrystalline silicon oxycarbide $\left(\mathrm{p}-\mu \mathrm{c}-\mathrm{SiO}_{x} \mathrm{C}_{y}: \mathrm{H}\right)$ is an appropriate description of the material. Furthermore, the lack of $\mathrm{CH}_{x}$ peaks in the FT-IR spectra indicate that the carbon incorporated is mostly bonded with silicon.

\subsection{Transmission electron microscopy}

To examine the structure of the deposited layers by transmission electron microscopy (TEM), the p-type layers were deposited on crystalline silicon (c-Si) wafers. We note that the growth mechanism of the layers is different on the glass substrates and c-Si wafers [28], but to develop a first understanding of the material, we nevertheless present such samples. Cross-section samples for TEM observation were cut into slices and glued face to face in a sandwich configuration, before being thinned, first mechanically then by ion milling, until they became transparent for the electrons.

Figure 9 shows a high resolution TEM (HRTEM) image of the layer deposited with 0.45 sccm of HMDSO flow rate, showing the grains of microcrystalline silicon. Parts 


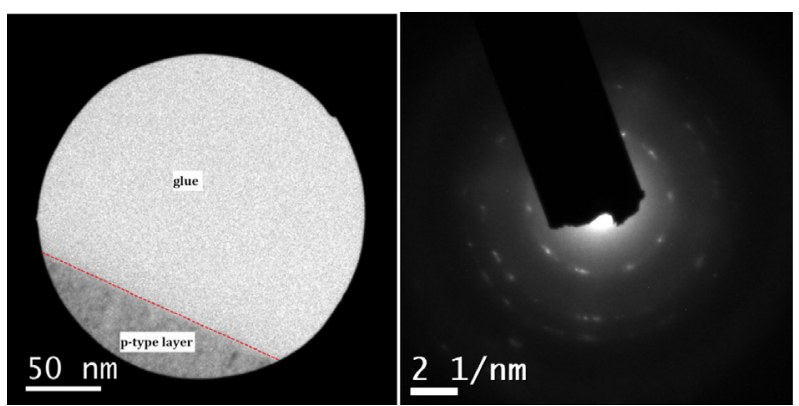

Fig. 10. Left: selected zone for diffraction pattern measurement. Right: diffraction pattern of p-type layer and glue.

of the image exhibiting no crystalline structure stem from the presence of amorphous regions in the film. This image is very similar to the one reported in reference [14] with clearly identifiable regions of microcrystalline silicon.

In order to see the crystalline quality of this sample, we applied the smallest aperture for area selection on a zone which includes the deposited layer and the glue as indicated in Figure 10 (left). The recorded diffraction pattern shown in Figure 10 (right) reveals three rings that are the signatures of $\{111\},\{220\}$ and $\{311\}$ crystallographic planes of silicon. On verifying the inter-planar distances of family of planes of silicon carbide $[29]$ ( $\{111\}$ for cubic $\mathrm{SiC}$ or $\{100\},\{002\}$ and $\{101\}$ for hexagonal $\mathrm{SiC})$, we note that there is no contribution from crystalline $\mathrm{SiC}$ in the diffraction pattern. The diffused part is mainly caused by the glue, but there is also a small contribution of the amorphous phase of the layer.

\subsection{Single junction $\mathrm{p}-\mathrm{i}-\mathrm{n}$ solar cells}

To test the p-type layers in devices, single junction p-i-n solar cells were fabricated. Figure 11 shows the resulting solar cell device parameters, displayed as a function of HMDSO flow rate. As indicated in Section 2, there were vacuum breaks at the $\mathrm{p} / \mathrm{i}$ and $\mathrm{i} / \mathrm{n}$ interfaces. To examine if the $\mathrm{p} / \mathrm{i}$ interface break has a greater impact on layers using HMDSO (relative to ones using no oxygen source or $\mathrm{CO}_{2}$ as the oxygen source), as well as to allow comparison of the performance of our $\mathrm{p}-\mu \mathrm{c}-\mathrm{SiO}_{x} \mathrm{C}_{y}: \mathrm{H}$ layers relative to more standard layers, reference $\mathrm{p}-\mathrm{i}-\mathrm{n}$ solar cells were also fabricated with the same vacuum breaks. The p-type layers for these reference cells are p-a-Si:H $\left(\sigma \sim 10^{-5} \mathrm{~S} / \mathrm{cm}, X_{c} \sim 0 \%\right.$ ) deposited with no oxygen source and $\mathrm{p}-\mu \mathrm{c}-\mathrm{SiO}_{x}: \mathrm{H}\left(\sigma \sim 10^{-2} \mathrm{~S} / \mathrm{cm}, X_{c} \sim 32 \%\right)$ deposited with $\mathrm{CO}_{2}$ as oxygen precursor. These cells are indicated on Figure 11 at an HMDSO flow rate of $1 \mathrm{sccm}$ $\left(X_{c} \sim 0 \%\right)$ and $0.30 \mathrm{sccm}\left(X_{c} \sim 35 \%\right)$, respectively.

Figure 11 shows that as the HMDSO flow rate increases, the device parameters $\left(J_{S C}, V_{O C}, F F\right.$, Efficiency) increase, up to $0.45 \mathrm{sccm}$ of HMDSO, and then decrease for higher flows. The maximum device efficiency $(5.5 \%)$ is obtained in the transition region from amorphous silicon to microcrystalline silicon at an HMDSO flow rate of $0.45 \mathrm{sccm}$, in agreement with previous reports [13]. We also note that at an HMDSO flow rate of $0.45 \mathrm{sccm}$,

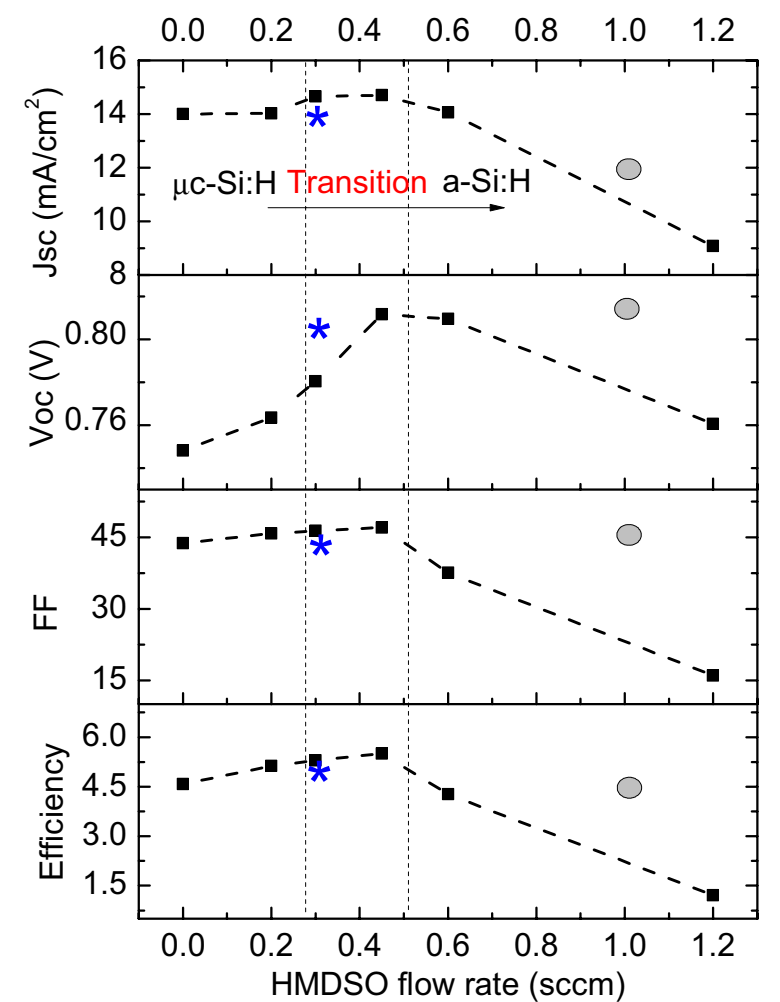

Fig. 11. p-i-n device parameters as a function of HMDSO flow rate. The parameters of a reference solar cell deposited with $\mathrm{p}$-a-Si:H is shown by $\circ$ and another reference solar cell with $\mathrm{p}-\mu \mathrm{c}-\mathrm{SiO}_{x}: \mathrm{H}\left(\mathrm{CO}_{2}\right.$ as the $\mathrm{O}$ source $)$ is shown by *.

$V_{O C}=0.81 \mathrm{~V}$ and $J_{S C}=14.7 \mathrm{~mA} / \mathrm{cm}^{2}$. The reference cell (p-a-Si:H) has $V_{O C}=0.82 \mathrm{~V}$ and $J_{S C}=12 \mathrm{~mA} / \mathrm{cm}^{2}$ and reference cell $\left(\mathrm{p}-\mu \mathrm{c}-\mathrm{SiO}_{x}: \mathrm{H}\right.$ using $\left.\mathrm{CO}_{2}\right)$ has $V_{O C}=0.80 \mathrm{~V}$ and $J_{S C}=14 \mathrm{~mA} / \mathrm{cm}^{2}$ and. Although poorer quality material is expected at the $\mathrm{p} / \mathrm{i}$ and $\mathrm{i} / \mathrm{n}$ interfaces because of the exposure of the layers to air (vacuum break) between subsequent depositions, this does not seem to impact the HMDSO layers any more than the reference p-a$\mathrm{Si}: \mathrm{H}$ and $\mathrm{p}-\mu \mathrm{c}-\mathrm{SiO}_{x}: \mathrm{H}$ layer. The desired effect of optical transparency of p-type layers is reflected by higher $J_{S C}$ in solar cells for $\mathrm{p}-\mu \mathrm{c}-\mathrm{SiO}_{x} \mathrm{C}_{y}: \mathrm{H}$ and $\mathrm{p}-\mu \mathrm{c}-\mathrm{SiO}_{x}: \mathrm{H}$ layers relative to the $\mathrm{p}-\mathrm{a}-\mathrm{Si}: \mathrm{H}$ layer.

The most deficient cell parameter for all the p-type layers is the $F F$, which is at most $45 \%$ rather than the expected $>70 \%$ for high quality devices. To help explore the cause of this (i.e. if it is due to series resistance, shunting effects, or recombination), Figure 12 shows the $J-V$ curves under light (measured between $-1 \mathrm{~V}$ to $1.5 \mathrm{~V}$ ) of p-i-n solar cells for different HMDSO flow rates.

Figure 12 shows that as the HMDSO flow rate increases, the $J-V$ curves get more and more "S-shaped". Even for the lowest HMDSO flow $(0.2 \mathrm{sccm})$, a kink can be observed in the $J-V$ curve. The presence of such $\mathrm{S}$ shapes indicates the presence of a counter-diode in the current path (as opposed to a straighter line at $V_{O C}$ or $J_{S C}$ which would indicate a true series resistance or "shunt resistance", respectively). As the $V_{O C}$ of the devices remain reasonable, it is most likely that the junction between the 


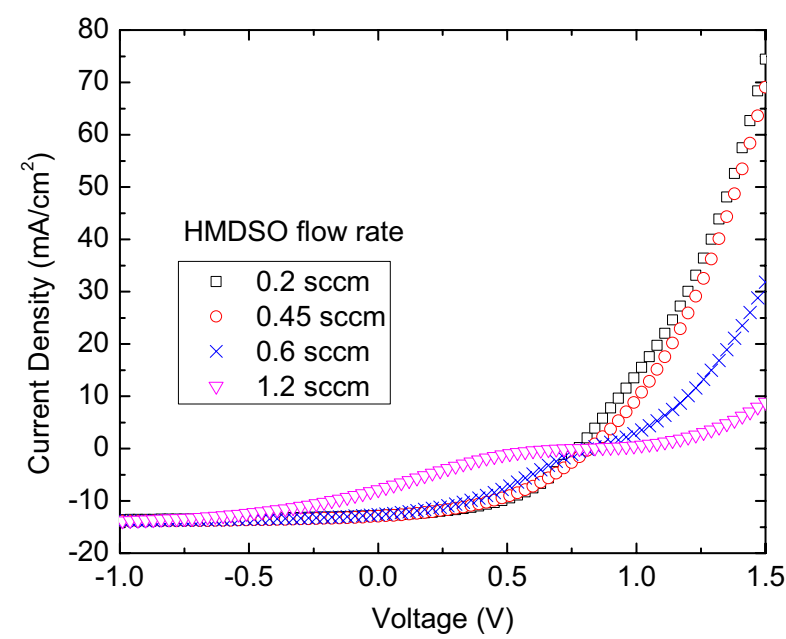

Fig. 12. $J-V$ curves of single junction p-i-n solar cells, for HMDSO flow rates from 0.2 to $1.2 \mathrm{sccm}$ measured between $1 \mathrm{~V}$ to $1.5 \mathrm{~V}$ under light.

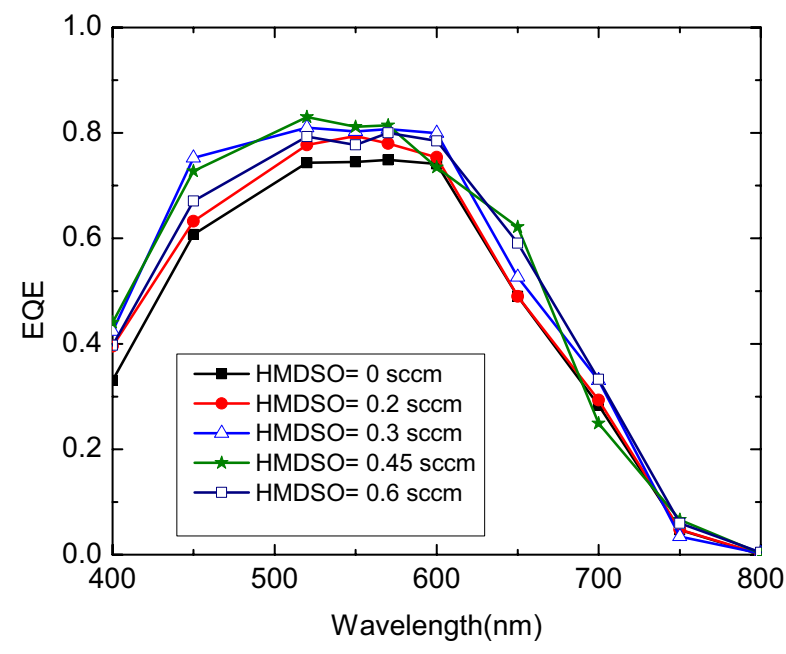

Fig. 13. EQE of the single junction p-i-n solar cells with increasing HMDSO flow rate.

$\mathrm{ZnO}: \mathrm{Al}$ and p-type layers is not ohmic, and this is limiting cell performance. This effect would be in addition to the negative effects of the vacuum breaks and any other process limitations (i-layer quality, $\mathrm{ZnO}: \mathrm{Al}$ ) causing relatively poor solar cell performance.

Finally, to check the absorption in the solar cells at different wavelengths, the external quantum efficiency (EQE) was measured under zero voltage bias and is presented in Figure 13.

Figure 13 shows that as the HMDSO flow rate increases, so does the EQE in the low wavelength region (400-500 nm) up to $0.45 \mathrm{sccm}$ of HMDSO flow rate. This confirms the desired transparency effect of higher $\mathrm{O}$ and $\mathrm{C}$ content in the layers. However, the EQE at low wavelengths decreases with subsequently increasing HMDSO flow. This is most likely due to the impact of the S-curve shown in Figure 12. The reason for the impact on the EQE in the higher wavelength region $(\sim 650 \mathrm{~nm})$ is not as clear - it may be due to poorer collection, but more likely variability in the texture and thickness of the $\mathrm{ZnO}$ :Al substrates.

\section{Conclusion}

In this work, we demonstrate the use of an easy-tohandle oxygen and carbon precursor, hexamethyldisiloxane (HMDSO) to deposit p- $\mu \mathrm{c}-\mathrm{SiO}_{x} \mathrm{C}_{y}: \mathrm{H}$ layers. It is seen that with an increase in HMDSO flow rate, the microcrystalline fraction in the layers decreases and the layers become more transparent because of the incorporation of $\mathrm{O}$ and $\mathrm{C}$. In comparison to literature results for $\mathrm{p}-\mu \mathrm{c}-\mathrm{SiO}_{x}: \mathrm{H}$, these layers have higher refractive indices for similar crystalline fractions. The additional incorporation of $\mathrm{C}$ in the films is effective in lowering the absorption (by forming a-SiC:H regions), but not as effective as incorporating the equivalent amount of $\mathrm{O}$. It is possible to control the refractive index in the range from 2.5 to 3.85 and dark conductivity in the range from 1 to $10^{-8} \mathrm{~S} / \mathrm{cm}$. Fourier transform infrared spectroscopy (FT-IR) studies reveal that HMDSO dissociates in the plasma and Si-O$\mathrm{Si}$ bonds are incorporated in the deposited layers. Secondary ion mass spectrometry (SIMS) analysis indicates that the atomic fractions of $\mathrm{O}$ and that of $\mathrm{C}$ in the layers are similar, indicating that the incorporation of $\mathrm{O}$ is six times more efficient than $\mathrm{C}$ when HMDSO is utilized as a precursor. A high resolution transmission electron microscopy (HR-TEM) image identifies regions of $\mu \mathrm{c}-\mathrm{Si}: \mathrm{H}$ in the deposited layer, and a selective area diffraction pattern (SAD) confirms the presence of $\{111\},\{220\}$ and $\{311\}$ silicon families of planes in the p-type layer. The layers were tested in single junction $\mathrm{p}-\mathrm{i}-\mathrm{n}$ solar cells and the best performance of the solar cells was observed in the transition region from $\mu \mathrm{c}-\mathrm{Si}: \mathrm{H}$ to a-Si:H. Presently, the non-ohmic junction between $\mathrm{ZnO}: \mathrm{Al}$ and p-type layer seems to be the limiting factor for these solar cells.

The work was carried out under a CIFRE Contract (2012/0892) between Air Liquide and LPICM, facilitated by the "Association Recherche National Technologie" (ANRT) in France. The authors would like to thank Olivier Schneegans at the LGEP for the conductive AFM image.

\section{References}

1. M. Berginski et al., Sol. Energy Mater. Sol. Cells 92, 1037 (2008)

2. K. Ding et al., Sol. Energy Mater. Sol. Cells 95, 3318 (2011)

3. F. Demichelis, C.F. Pirri, E. Tresso, Philos. Mag. 66, 135 (1992)

4. P. Sichanugrist, T. Sasaki, A. Asano, Y. Ichikawa, H. Sakai, Sol. Energy Mater. Sol. Cells 34, 415 (1994)

5. P. Cuony et al., Appl. Phys. Lett. 97, 213502 (2010)

6. S. Inthisang, T. Krajangsang, I.A. Yunaz, A. Yamada, M. Konagai, C.R. Wronski, Phys. Status Solidi C 8, 2990 (2011)

7. A. Sarker, A.K. Barua, Jpn J. Appl. Phys. 41, 765 (2002) 
8. S.N. Abolmasov et al., EPJ Photovolt. 5, 55206 (2014)

9. P. Cuony et al., Adv. Mater. 24, 1182 (2012)

10. P.D. Veneri, L.V. Mercaldo, I. Usatii, Prog. Photovol.: Res. Appl. 21, 148 (2013)

11. A. Lambertz et al., Sol. Energy Mater. Sol. Cells 119, 134 (2013)

12. P. Buehlmann et al., Appl. Phys. Lett. 91, 143505 (2007)

13. K. Sriprapha, N. Sitthiphol, P. Sangkhawong, V. Sangsuwan, A. Limmanee, J. Sritharathikhun, Curr. Appl. Phys. 11, S47 (2011)

14. C.-N. Li et al., Int. J. Photoenergy. 2012, 1 (2012)

15. A. Lambertz, F. Finger, R.E.I. Schropp, U. Rau, V. Smirnov, Prog. Photovol.: Res. Appl. 23, 939 (2015)

16. V. Smirnov, A. Lambertz, S. Tillmanns, F. Finger, Can. J. Phys. 92, 932 (2014)

17. K. Haga, K. Yamamoto, M. Kumano, H. Watanabe, Jpn J. Appl. Phys. 25, L39 (1986)

18. A. Hartstein, D.R. Young, Appl. Phys. Lett. 38, 631 (1981)
19. V.A. Gritsenko et al., Microelectron. Reliab. 43, 665 (2003)

20. D.S. Kim, Y.H. Lee, N.-H. Park, Appl. Phys. Lett. 69, 2776 (1996)

21. D. Trunec et al., J. Phys. D 43, 225403 (2010)

22. A. Sonnenfeld et al., Plasmas Polym. 6, 237 (2001)

23. J. Muller, B. Rech, J. Springer, M. Vanecek, Sol. Energy 77, 917 (2004)

24. G.E. Jellison, B.C. Sales, Appl. Opt. 30, 4310 (1991)

25. P. Cuony, Optical Layers for Thin-film Silicon Solar Cells, Ph.D. Thesis, EPFL, 2011

26. G. Yue, L. Sivec, J.M. Owens, B. Yan, J. Yang, S. Guha, Appl. Phys. Lett. 95, 263501 (2009)

27. D. Magni, C.H. Deschenaux, C. Courteille, A.A. Howling, C.H. Hollenstein, P. Fayet, MRS Proc. 544, 65 (1998)

28. P. Roca i Cabarrocas, N. Layadi, T. Heitz, B. Drèvillon, I. Solomon, Appl. Phys. Lett. 66, 3609 (1995)

29. S.R. Nutt, F.E. Wawner, J. Mater. Sci. 20, 1953 (1985)

Cite this article as: Prabal Goyal, Junegie Hong, Farah Haddad, Jean-Luc Maurice, Pere Roca i Cabarrocas, Erik Johnson, Use of hexamethyldisiloxane for p-type microcrystalline silicon oxycarbide layers, EPJ Photovoltaics 7, 70301 (2016). 